\title{
Man and Future: a Palaeontological and Chronological Foundation of Cassirer's Definition of Man as Animal Symbolicum
}

\author{
Luigi Laino \\ (Università di Napoli Federico II, llain031@gmail.com)
}

\begin{abstract}
Die Charakterisirung des Menschen als eines vernünftiges Thieres liegt schon in der Gestalt und Organisation seiner Hand, seiner Finger und Fingerspitzen, deren theils Bau, theils zartes Gefühl, dadurch die Natur ihn nicht für eine Art der Handhabung der Sachen, sondern unbestimmt für alle, mithin für den Gebrauch der Vernunft geschickt macht, und dadurch die technische oder Geschicklichkeitsanlage seiner Gattung al seines vernünftigen Thieres bezeichnet hat (Kant 1880, 255).
\end{abstract}

\section{Introduction: The Question of Man in the Light of the Philo- sophical Anthropology and Its Relationship with Science}

Since the rise of the philosophical anthropology the question of man has been addressed in a renewed way in respect of the classically philosophical tradition. The distinctive aspect of the innovation is of course the strengthening of the relationship with science: the philosophical consideration of man cannot put aside the urgency of a confrontation with the most recent results achieved in the field of those sciences concerning man as a scientific object. It follows that the worth of the philosophical analysis depends on the possibility of validating the philosophical statements, taking in consideration their scientific coherence.

This methodological issue seems to represent a precise heritage of the old Kantianism, according to which between the transcendental method - i. e. philosophy - and the mathematical physics - i. e. science - ran a precise interconnection. Hence the epistemological status of the philosophical anthropology seems to be comparable with that of the upheld "particular metaphysics of nature" in Metaphysische Anfangsgründe der Naturwissenschaft (Kant 1911, 469-479), insofar as the necessity of basing the validity of the philosophical statements on the scientific results does not hamper the metaphysical tension of the philosophical inquiry. The philosophical anthropology seems to look for a systematic connection of all those data coming from the field of science, but 
in this process it autonomously elaborates the meaning of the scientific results and reaches an abstracter and comprehensive explanation. Its main achievement could indeed summed up in a general definition of the essence of man, even though this essence has completely lost its metaphysical configuration and presents itself with a dynamical tension. This inner tendency can be considered as a shared presumption by all the authors, and can be reconstructed starting from an apparently divergent opinion, upheld by the biologist Jakob von Uexküll. He developed a theoretical biology warmly inspired by Kant's thought, sketching a functional theory of perception, according to which every living being is capable of forming its own environment (von Uexküll 1928, 1-3, 99-100; Kriszat-von Uexküll 1956, 19-30). However, if this definition is in contrast with the generally anthropocentric argument of the "animal rationale", and seems to refute the difference between "man" and "animal" - which they are both now capable of forming their own world -, we must notice that the capacity of building the different connections laying the foundations of the different "environments", reveals a different degree of freedom in the human sphere. In respect of Streifzüge durch die Umwelten von Tieren und Menschen, Adolf Portmann (Portmann 1956, 10-11) has pointed out that this human specificity consists in the individuation of the unity of the "comprehending" (Verstehen or Verstehensmöglichkeit), because the circumstance that in the same species rises up the possibility of discerning between the different sorts of connections and environment building (the oak of the old man, the oak of a young boy, the ray of light of the physicist and that of the physiologist etc.; Kriszat-von Uexküll 1956, 94-101), can be solely explained by bearing in mind the general form of intentionality, according to which the different "world" shapes can be derived. In a few words, a new level of acquaintance seems to be gained, in the human dimension, as regard the world forming capacity.

The possibility of reaching the unity of meaning, which is witnessed by von Uexküll by recalling the concept of the unity of nature behind the apparent diversity of the different natures of the chemist, of the physicist etc. (Kriszatvon Uexküll 1956, 101), is the decisive step allowing us to figure out the human "interior world" (Innenwelt) as a symbolic one. In von Uexküll's theory, there is, as we have stated before, a precise degree of freedom for each species, insofar as between «Merkwelt» and «Wirkwelt» takes place the «Innenwelt», a special answer of the living being to the stimuli coming from the external world (Merkwelt). Through the action of this interior world, the external environment seems to be shaped by an inner power of the living being, which is however specific to every different living being. This means that in principle every shaped world is different from the other (there is no common world to birds in general, but solely the hawk's world, the eagle's world etc.). Hence Portmann, as we have clarified before, underlines that the danger lies in the attempt to acritically apply the Umwelt theory to man, since the unity of the comprehension has been discovered. The predominance of the unity of mean- 
ing implies indeed the emergence of a peculiar distance between man and the biological constitution of his environment, so that his action and his theoretical activity solely take place within this distance: if we can for sure take for granted that the world of a young man is not the same world of a skilled physician, we can at the same time depict the general form of the connection leading to the particularization of each environment. This implies that we must seek a special principle of the "forming" in the human interior world, which overcomes every specialization, and that, however, makes the latter possible. Nevertheless, I must confess that the present paper will not address the question of the particular side of the "forming", but it will be rather focused on the definition of the general aspect of the acting. According to the mentality of the philosophical anthropologists and of the transcendental philosophy, it will endorse a confrontation of the philosophical theory with science's achievements: I should particularly show, from the one hand, how much the capacity of stepping back from his environment is somehow biologically constitutive for the human being - and I know, there is already something out there -, and, from the other hand, how in the code of biology is written the grammar of the human symbolic freedom. In order to do that, I shall compare Cassirer's definition of man as "animal symbolicum" with Leroi-Gourhan's palaeoanthropology.

At the basis of this aim there are several reasons, but the most important one is the following. From the transcendental point of view, it should always be possible to describe a "metaphysical" theory which is prior to science, but it cannot leave behind the reference to scientific data and results. However, science is always in progress and goes through both paradigmatic and specific changes: the question is here whether to this mutations in the scientific field do correspond some modifications of the philosophical system of knowledge. Cassirer's answer to this tough problem is that these modifications are not only possible, but also necessary, because the history of science is the history of the discovery of the a priori functions of reason; according to this approach, the logical structures of reason reveal themselves through the evolution of science, and thus they can apparently change, but at the end of this process we can always find something which is pretty stable and that can just be envisaged as an a priori (Cohen 1987, B6/C10; Cassirer 1999, 13). Nevertheless, this "functionalization" of the a priori (Ibongu 2011, 29; Ferrari 1996, 119120) compels us to recognize that the metaphysical structure of a philosophy of science can never be considered as a definitive system, and that this system must be revisited every time that within science significant changes have been occurred. Even though Cassirer himself has faced the consequences of this dynamics of the a priori (see Ferrari 2003, 142-148), the task of comparing the metaphysical part of the system with what comes from scientific knowledge can never be considered as an ended task. The open confrontation between philosophy and science must be indeed an infinitive purpose of the critical 
method, and this basically means that a result achieved in the philosophical field have to be always "up to date" as regards the posterior evolution of science. If we have sketched a functional theory of knowledge starting from classical mechanics and from the physics of the 19th century, we are compelled to verify this approach by testing it with the results of the theory of relativity and those of the quantum mechanics. This must remain valid for the philosophical anthropology too. If we would like to prove Cassirer's definitions, we must not only limit ourselves to sketch the relationship between Cassirer and the scientific theories he referred to and that he expressly quoted, but we have especially to bring into play those scientific issues arose after him. This is very important, insofar as if we solely describe Cassirer's direct references we would obtain a circular explanation: it is fairly clear that Cassirer's philosophical theory is proved according to the sources he used. This is the reason why we must take in consideration Leroi-Gourhan's work, flourished a few years later Cassirer died in 1945. Leroi-Gourhan's pivotal book - Gesture and Speech - is not only a document in which the palaeontological research was brilliantly and profoundly explained, but also a magnificent compendium of philosophical anthropology. The study of the human evolution affords him the possibility of describing, alongside the punctual explanation of the development of the anatomical and physiological characteristics of the species, the inner process which links the biologically technological disposition of man to its symbolic meaning. Man's evolution can be regarded as a continuous history of "liberation": from the first paleoanthropian, whose erect posture implied the freedom of the hand from the ground and the consequent development of the brain and skull, to the invention of graphism, we can follow all the progressive liberations that, starting from biology, culminate in the final stage of a spiritual dimension, into which the relationship with the external world is guided by symbols.

This does neither mean of course that we will exclusively focus on the attempt of validating Cassirer's theory through Leroi-Gourhan's palaeontology, nor that we will interpret the latter as a mere confirmation of the former; we must rather seek a more general formulation, according to which the profound reasons of the one can become those of the other. We have basically to show that the symbolic tension of the human acting can be derived from the biological evolution of man, as well as this evolution, seen as a history of liberations, can be interpreted as a general symbolic tension, whose articulation can be conceived on the basis of a phenomenological theory of Spirit: there are different degrees of "freedom", within which every stage represent a "level" of the consciousness of the process of liberation. We will have, for instance, the first stage of the biological liberation, characterized by the mere freedom from the ground and the definition of the anatomical basis of the humankind, in which the degree of freedom is very low; then we will go through the development of a more and more sophisticated technological ability, by means of which man 
becomes able to manipulate reality through the fabrication of complicated artifacts; as third moment, we will observe the emergence of the first form of socialization and so the rise of the primitive culture, which has been made possible by the parallel evolution of language. Each stage implies, as stated above, a liberation from the biological nature, till the point that in the form of language our link to the biological world seems to be lost: through the capacity of "naming" things, we become master of things and thus of nature itself ( $G n$ 1:26-2:25). The symbolization and the liberation still show, in any case, their biologically technological roots, insofar as language as well as science are typically conceived as systems of signs, viz. as syntactical codes whose basic characteristic is the fact that we can operate with these signs (von Helmholtz 1867, 443). Ethics can even be interpreted according to this scheme: maxims and imperatives are statements concerning the "right" form of acting, and the real actions can be viewed as "means" to reach the symbolical status of the idea of Good, in which every influence of the biological impulse has been completely transfigured.

\section{The Threshold-Argument and the Definition of Man as "Ani- mal Symbolicum"}

Cassirer's "animal symbolicum" clearly has a continuous relationship with the classic philosophical definition of "animal rationale". From a logical point of view, both the arguments are based on the possibility of individuating a threshold between what is still animal and the specification of the human form of the living. The threshold-argument is typical of the philosophical tradition and mainly of the philosophical anthropology (Scheler, Plessner, Gehlen); this implies that the main task of the theory becomes that of describing the rules and the criteria according to which a well-defined border can be found. There is a basic form of life corresponding to the position of man, whose access is denied to all other forms of living beings. Furthermore, both the definitions imply an anthropocentric position, even though the "animal symbolicum" does not share the metaphysical implications of the "animal rationale" and appears to be scientifically proved ${ }^{2}$ : the symbolic tension as constitutive element of

1 On this classical topic of the philosophical anthropology (see: Schacht 2015, 56).

2 When we are saying "scientifically proved", we mean the fact that the definition of "animal symbolicum" is argued moving from the scientific context. Hence the structure of the argument is strictly phenomenological: the starting point is the analysis of the animal behaviour and language, about which no symbolical dimension seems to be upheld. This can be explained by recalling the incapacity of animals to withhold their relationship to environment, and the assumption that their language does not overcome the expressive level. On the contrary, the experimental data especially concerning the patological conscience do show how the characteristic aspect of human intelligence consist of the symbolic organization of reality. Aphasic patients are in fact unable to solve abstract problems (for instance the subsumption of the different tonalities 
human identity is indeed derived from a precise comparison with modern biology and psychology, especially with Jakob von Uexküll and Wolfgang Köhler, and with neurophysiology, considering the intellectual relationship that Cassirer had with Kurt Goldstein.

\section{Metaphysical Biology or Biological Metaphysics?}

In Cassirer's anthropology, the scientific basis of the definition of "animal symbolicum" is particularly clear. At the same time, this approach appears to be conditioned by the transcendental point of view. According to Cassirer's view, life is an immediate whole, where man's activity is characterized by shaping a transcendent level into the immanence of life - on the latter point Cassirer himself quotes Simmel $(1922,13)$. This kind of representation prevents us from strictly overcoming phenomenal experience, but it also allows us to take into account the specific activity of man in the realm of nature: as a consequence, man is that living being deep-rooted into his biology, but capable of reversing this trend through the use of the symbolic faculty.

As a consequence, it is not clear if it is better to talk of a "metaphysical biology" or of a "biological metaphysics". In his posthumous project of a metaphysics of symbolic forms, the distinction between «Geist» und «Leben» seems to speak in favour of a separation between metaphysics and biology, but the phenomenological approach heads in a different direction (Itzkoff 1971, 175). Geist means, in fact, not a higher dimension than the immediateness of Leben, but rather a different consciousness of the unity of life (Sissel Hoel 2012, 73):

The essence of the fully concrete life "is (not something which is added to its own being, but something building its own being); that transcendence is immanent to it". In this inner and necessary duality, life appears not solely as the primitive source of spirit, but also as its archetype and prototype. Indeed, the same duplicity is present in a renewed and empowered form into the being of spirit. The growth and empowerment means that spirit not simply has this duplicity in itself as a part, but it knows of it too (Cassirer 2003, 11).

Hence, we can argue that Cassirer's point of view can be interpreted in the light of a biological metaphysics ${ }^{3}$, viz. by bearing in mind the unity and

of green under the general concept of the green colour), and this seems to suggest that the decisive faculty of humand mind lies in the capacity of the abstract and symbolical organization of reality (see Cassirer 1944, 44-86; Cassirer 1957, 205-278).

${ }^{3}$ Metaphysical biology seems on the contrary to be moving in the opposite direction. They both underline the close relationship between the general anthropological statements and their scientific origin, but in the case of palaeontology the tendency is to uphold, despite a clear upturning, the biological roots of every definition. Thus, one can say that a biological metaphysics seeks for a scientific foundation of its metaphysi- 
uniqueness of life, but showing how man's activity opens up a space for the determination of a transcendent window, within the realm of the immanent living (Sissel Hoel 2012, 78; 86-89; Renz 2002, 266-272). Accordingly, "spirit" is the name describing the consciousness of the mediated character of the immanence of life, and can be solely known through its objective forms, viz. through the symbolic forms (Bayer 2001, 44-45). The compatibility of such a vision with the results of science can be sustained as well by recalling the specific nature of the principle of "finality" within biological sciences, that Cassirer, following Kant's Kritik der Urteilskraft, interpreted as a maxim and as a heuristic principle: from this point of view, the unity of life, which is the unity of nature, solely means a functional scheme introduced by natural researchers in their work, but not a substantial quality of nature or of being itself (Cassirer 1950, 118-216).

\section{The Difference Between "Rational" and "Symbolic" and the Meta-Environmental Character of Human Acting}

At this stage of argumentation we must point out a difference running between the concept of "rational" and that of "symbolic", as regard Cassirer's thought as well as for the philosophical anthropology in general. On the one hand, the confrontation with ancient metaphysics ends with the substitution of the universally rational attribute with its specification as symbolical activity. Every rational move is as such symbolic, because it presupposes the capacity, for man, of overcoming the immediate environment, to assume a transcendent position in the continuity of the living. What is rational is not a particular product or even a universal shape of logos (speech, thought etc.), but logos in its own activity. On the other hand, it is clear that Cassirer wanted to lay the foundations of a functional metaphysics, according to which the unity of the whole is not rejected as such, but transcendence itself is represented as well as a constitutive part of the unity of being. In order to do that, there is only the way mentioned above: setting up the pure activity of thought as the very sense of reason. This framework immediately brings us to the question of technology.

In its fundamental meaning technology is for sure activity. As a consequence, a theory of technology should provide a general account of the different forms of the acting. But technology itself might be viewed as the peculiar form of intelligence gained by man over the course of history. Leroi-Gourhan's work has been seminal in that regard, and has showed how the technological ability is biologically inherent to man. In his account, the development of the technological capacity depends on a whole anatomic framework, which represents the

cal content, whereas a metaphysical biology tries to show how the metaphysical content can be genealogically derived from science itself. 
basic set of conditions of human species. The transcendental definition of man gained by palaeontology is then different from the classically philosophical one, since the conditions of possibility are not merely logic, but it generally complies with the higher principles of transcendental mentality. Still, this is not the point; indeed, the palaeontological interpretation gives us new tools to better reconsider Cassirer's definition.

In the spirit of transcendental mentality, the confrontation with science is in fact unavoidable: without a scientific reference, philosophical statements could uniquely be meta-empirical. This means that they would say nothing of experience - as is clear, this status pertains to a priori forms or concepts, but the rest of the concepts have to be linked to experience (Kant, $\mathrm{KrV}, \mathrm{B} 75-\mathrm{A} 48$ ). In order to make of the "animal symbolicum" a concept with an empirical content, we must then seek for a scientific grounding, capable of providing an empirical confirmation of the logical task of that concept.

As stated above, the comparison of the philosophical position to palaeontology allows us to address this question. From Cassirer's point of view, symbolic activity is the capacity of man of transcending the mono-dimensionality of the natural state: animals and aphasic subjects are not able to solve puzzling questions, which would need of the help of an "external" element. To reach the solution of this kind of problems, mind should be supported by the faculty of thinking beyond the immediate environment. Symbolic thinking is then metaenvironmental thinking (Cassirer 1944, 42-79; Cassirer 1957, 205-278). This character of human activity is confirmed by the palaeontological analysis: the succession of the evolutionary stages of man seems to validate the vision of the symbolic activity as characterizing aspect of human acting (Itzkoff 1971, 174-175).

\section{The Rise of the Question of Technology: Symbolics ${ }^{4}$ of the Technical Gesture}

According to Leroi-Gourhan, there are three basic elements to define mankind: 1) erect posture; 2) diminution of prognathism and spreading of the cortical fan; 3) freedom of the hand (Leroi-Gourhan 1993, I, 18-24). We must obviously focus on point (3). The assumption of the standing position, acts on the general organization of the skeleton, and puts the hand in a significantly renewed place within biological evolution. First of all, the freedom of the hand implies the liberation from all those biological tasks accomplished by paws in other animals. This notion of "liberation", which seems to share an important concordance with Gehlen's Entlastung (Gehlen 1988, 54-65), means that the function of the human hand is not solely connected to biological needs, such as

\footnotetext{
${ }^{4}$ I use the term "symbolics" in the same way according to which we speak of semiotics, logics or mathematics.
} 
eating, predation, walking etc. It is as though the evolution of man set up the conditions of possibility to individuate a field of transcendence within the immanent living activity of man, conceived as biological being, through this peculiar isolation of the hand. Freed from the ground - from his belonging to Earth - and from its biological chains, a new kind of acting becomes available to the hand, which means above all: freedom from biology. Accordingly, we have the two stages of the whole process: i) the biological liberation; ii) and the freedom from biology. It is important to stress the difference between these moments: on the one hand, the biological liberation only means that a first grade of independence is already realized within the biological structure; on the other hand, the freedom of the hand entails the liberation of a specific kind of gesture, having no resemblance with the animal world, and whose consequences are far from being clear in these first steps.

This authentically biological foundation of culture as natural dimension of humanity gives us the starting point to envisage a general theory of symbolic activity as characterizing element of humanity. Technology might then be interpreted as another face of the same symbolic coin. The technological activity is that specific form of acting embodied in a freed hand, whose symbolic meaning consists of the liberation of the human gesture from the biological envelopment of man's body. Furthermore, technology promptly compels us to think in symbolic terms. The fabrication of a tool is indeed directly connected with the capacity of solving problems in a meta-environmental context; to consciously build a chopper as weapon, we are obliged to go beyond the presence of the stone, since it is necessary to presuppose both a scope and a paradigm of the object we are going to construct. As a consequence, the biological freedom of the hand sets out the conditions of the technological activity, but the technological activity is basically symbolical, implying the meta-environmental element. This meta-environmental element is actually original, even though technological actions seem to be firstly related to matter. The circumstance that the different technological activities are organized under the primacy of a determined material element, such as water, fire etc. (Leroi-Gourhan 1971, 922), does not change the fact that technology is already acting5.

In turn, the rise of rationality as distinctive attribute of man is in any case strictly connected to the anatomical evolution, since the adaptation of the skeleton to the erect posture causes modifications in the conformation of the skull. The spreading of the cortical fan is the result of the adaptation of the human brain both to the renewed physiognomy of the skull and to the new

\footnotetext{
${ }^{5}$ The mutual belonging of matter and spirit has been recently upheld by Coccia: "It is in the stones, indeed, that the human intelligence has come out from the space of interiority, to incarnate itself in the world of things. Used, worked or sculpted, stone is the primordial object, the most ancient vehicle of the human spirit, the first form of culture" (Coccia 2014, 17), who besides explicitly quotes Leroi-Gourhan in a footnote (see 1971, 115).
} 
technological possibilities: brain becomes bigger, and the neurological network structures itself according to the implications of a freed hand. The whole structure then predisposes man's face to the birth and the use of language.

From this point of view, one can say that technology and language are the two inextricable aspects of a human symbolic rationality. In fact, we must bear in mind that not solely language is symbolic, but also that the technological activity has a symbolic meaning: human acting is both technological - because the freed hand is capable of creating and using tools - and symbolical the production of tools implies the meta-environmental and paradigmatic capacity. This means that a history of technology is at the same time history of reason, and that a genealogy of language is a direct consequence of an enquiry upon technology (Leroi-Gourhan 1993, I, 112-116).

\section{Biology of Society and Philosophy of Culture}

Leroi-Gourhan's anthropology must be interpreted in the light of a metaphysical biology, but the peculiar upturning originated by the rise of the human consociations confirms the exceptional character of human culture: here the rhythms of the evolution of humanity as phylum have been overcome by an autonomous orientation. The idea of biology of technology entails a double level of liberation (nature-society-culture), since biology of society compels us to recognize that the evolution of human societies follow a specific rhythm, which is at the same time a reflection and an independent reconfiguration of biological evolution. The problem concerns how much of the biological rhythms penetrates into the realm of the evolution of societies, considering that the analysis of technology shows the possibility of individuating an evolutionary progress which is similar to the biological evolution' ${ }^{6}$. Leroi-Gourhan introduces the question of biology of society and of biology of technology in the fifth chapter of Technics and Language (Leroi-Gourhan 1993, I, 145-147). In order to find a definition of biology of society and of biology of technology, we must take into account two excerpts of Memory and Rhythms: i) "This enmeshing of tools and gestures in organs extraneous to the human has all the characteristics of biological evolution because, like cerebral evolution, it develops in time through the addition of elements that improve the operation process without eliminating one another" (Leroi-Gourhan 1993, II, 242); ii) "Generally regarded as historical phenomena of technical significance, the invention of the four-wheeled carriage, the plough, the windmill, the sailing ship, must also be viewed as biological ones - as mutations of that external organism which, in the human, substitutes itself for the physiological body" (LeroiGourhan 1993, II, 246). I briefly dealt with the question, to underline how the

${ }^{6}$ Audouze has noticed that this inner tension proper to technology might have a link to Bergson's élan vital (Audouze 2002, 293-294). 
different liberations realized through the broadening of the technological gesture lead us to the recognition of a specific phenomenon called "exteriorization": "We saw earlier that in humans, the mobility of tools and language has determined the exteriorization of operational programs related to the survival of the group" (Leroi-Gourhan 1993, II, 238). "Exteriorization" is another trace of the symbolical attitude of the technological gesture: "This detachment, which expresses itself in the separation between tool and hand and between word and object, is also reflected in the distance society creates between itself and the zoological group. The whole of our evolution has been oriented toward placing outside ourselves what in the rest of the animal world is achieved inside by species adaptation" (Leroi-Gourhan 1993, II, 235). One can observe this passage in Cassirer too, since the anthropological turn and the question of the phenomenology of life brings to a reconsideration of the three-way division of Philosophie der symbolischen Formen: Ausdruck (expression), Darstellung (representation) and reine Bedeutung (pure meaning), in favour of a functional dialectics of Ausdruck (Plümacher 1996, 136-138; Möckel 2005, 340343).

Nevertheless, human intelligence implies a third level of emancipation acting on the consolidation of the mechanical operational sequences: the organization of brain is so complex, to the point that the selection and the choice among these sequences has reached a high degree of freedom in respect both of the phyletic heritage and of the social transmission (Leroi-Gourhan 1993, I, 145-147; II, 219-236). From this point of view, one can undoubtedly affirm that the very realm of humanity is the world of culture (Cassirer 1944, 87-96; Bayer 2001, 45-46).

\section{The Ontological Grounding of Future}

The settlement of a symbolics of the technical gesture leaves room for a chronological analysis of human acting. Indeed, the meta-environmental character of man's activity implies a peculiar orientation of every gesture toward what is not immediately present. Human activity always recalls something which is not "on hand".

It is worthwhile to study this situation according to the threshold-argument. Animal acting is of course carried out by something which is not present, and that we may identify as an acquired experience: for instance, the disputes for the territory are regulated by a consolidated language, which is solely not effect of the instincts. The same word "instinct" is actually misleading: Cassirer was perfectly aware of animal intelligence (Cassirer 1944, 59-60), and according to Leroi-Gourhan the consolidation of the operational memory must imply the recognition of a peculiar form of intelligence (Leroi-Gourhan 1993, II, 230234). Since it rises up out the codification of some mechanical operations, "in- 
stinct" is already "intelligence". There must be a sort of transmission between the different generations, so that one can say that the memory of operational sequences is a shared characteristic of men and animals. However, it must be pointed out that the distinctive attribute of man's memory is its degree of freedom in the choice of the different sequences, as well as the refinement of a specific form of language overcoming the mere expression of needs or feeling (Cassirer 1944, 44-62; Leroi-Gourhan 1993, II, 221-227; 236-237). Indeed, the invention of words as stable support of the meaning of actions deals the cards afresh. The sphere of meaning is, within human context, crystallized through the possibility of making clear and unambiguous references to non-present contents, whereas the meaning of an animal action is deep-rooted in the present to which it belongs. The creation of stable signs involves the rise of a specific form of manipulation. The vocal expression of an inner content cannot be available for another animal after its actual use; this happens because the communicative intention ceases with the action itself, insofar as it has reached its goal of expressing feelings of fear, domination etc.7; simply put, an animal sign cannot be used by another animal in a successive moment as it were the same sign, and it will never become a word.

From this point of view, the rise of the chronological determination of man appears to be clearly oriented toward the future. This spreading is directly connected to the technological manipulation of signs, because, as we have already seen, the creation of signs implies their constant availability. Futuristic dimension, meta-environmental tension, technology and symbolic faculty are solely four aspects of the same process.

Hence, the future availability of signs is the characterizing element of the human symbolic acting. The interrelation of the symbolic and of the technological dimension is here unavoidable, and the definition of a basic point of view by means of which solving the question of human acting could not leave aside this element.

In short, we have at least three reasons according to which the symbolicity of the technical gesture can be argued for:

i) The fact that technological capacity rises up as a consequence of the biological freedom of the human hand seems to recall the meta-environmental element which is peculiar to the definition of the symbolical worth of human acting; from this point of view, we may also say that there are not two different sorts of actions, but rather a unique form of activity which can be actualized

\footnotetext{
${ }^{7}$ Aristotle himself, defining man as the only living being having logos, was fully aware of the communicative capacity of animals: the difference between men and animals is not that of having language, if language is the capacity of communicating feelings (aisthēsis) through voice (phōnē), but rather the possibility of discussing of Good and Evil, of what is useful or unuseful through language. From this point of view, it is clear that human language must be represented as a radically different form from a generic shape of emotional expressivity pertaining to animals too (Pol. I, 1253a1-18).
} 
through these two basic configurations (the technological action and the symbolical one). This can be confirmed by the addition of the esthetical faculty as a third specific form of human acting. Nevertheless, as I have already pointed out, it is important to hold the distinction between biological liberation and freedom from biology: the first is the result of a bio-mechanical process, whereas the latter is the consequence of this process. The step made from the first stage to the second one is the invention of gestures, viz. the aesthetical development of motility. Between the two dimensions, we also find the rise of society.

ii) The fabrication of artefacts presupposes the existence of a paradigmatic model of the acting. Philosophy has broadly focussed on this topic, as Plato's theory of ideas clearly shows. The technological relationship running between sensitive beings and ideas is explained through the demiurgic metaphor, and the same definition of natural being is somehow arguable only according to these technical terms. Knowledge is genealogically linked to the technological manipulation, since beings solely become knowable within the reference of thing to that idea working as paradigm. The knowability function is implemented by demiurge's action, which puts into things the reference to an ideal meaning, and made them signs of ideas - according to Plato's Timaeus, things are ta dia nou dedemiourgèmena (Tim. 47e4). The production and the creation of a thing as sign ${ }^{8}$ is of course metaphoric, but it represents the final philosophical transposition of the technical gesture. However, the shape of the paradigmatic structure is crucial as well. It is not by chance that Leroi-Gourhan depicts the question of technology through the reference to the lithic industry, and that the point of divergence between human technology and a generic acting through means is represented by the conscious creation, viz. by the capacity of man of directing the fabrication process (see also Aristotle's Physics, e.g. 194b7-8). Hence, we speak of technological action when we can individuate a process according to which a thing is created under the work of a specific model, whose function corresponds to a certain network of impulses and goals. Technological acting is constitutionally symbolic, because its structure is strictly paradigmatic (de Villers 2007, 97-98).

iii) In human kind there is a precise relationship face-hand, and the genealogy of language solely becomes possible under the star of a genealogy of technology. There is a special agreement between the development of the technological faculty and the linguistic one, until the point that the parallelism tool-word actually becomes dominant in the description of human evolution. Mutatis mutandis, words behave in the same way as tools do (Leroi-Gourhan 1993, I,

8 The acknowledgment of this character of thing has been always figured out over the history of idealism. It is sufficient here to remind Plato's account, according to which thing is $m \bar{e}$ on, inasmuch as it is sign of the ontōs on of an idea. 
34-36): they are the instruments of the symbolic manipulation of reality. Words allow man to free himself from the environmental context, because they allude to the possibility of abstract meanings, and can be considered valid not only within the situation into which they are arisen and used, but they are henceforward available to all those who will be able to put that use in their own hands. Moreover, the consolidation of a vocal signal in an objective sign is accompanied by the emerging of a specific question on the relationship of signs between each other. It is possible to very soon set up the question of a technological theory of the use of signs, according to which words are indeed nothing but tools. This conception had great luck in the history of philosophy, beginning from Plato (Crat. 388b and ff.), and the history of idealism has shown its importance especially in Leibniz' idea of a Characteristica universalis (Cassirer 1998, 124-125).

The unavailability of signs determines the chronological dimension of human acting. This dimension is literally utopian, since man is constantly projected beyond his own environment ${ }^{9}$. In the first stages of this process, the projection does not reach a specific social meaning and still less the realm of ethics, which is only a very late product of human evolution and culture ${ }^{10}$, but one may conjectures that this utopian tension has been already prepared within the biological context.

Not only Cassirer's An Essay on Man is very clear on the utopian tension of humanity towards future, but his whole ontology confirms this idea. Cassirer's

\footnotetext{
${ }^{9}$ It must be said that in the modern era of technology, the meta-environmental character will be contrasted by the rise of a specific form of tension, flowing in the opposit direction to meta-environmentality, which can be called "neo-environmentality". It is related to the hypostatization of the counter-movement pertaining the technical acting: once man is distanciated from his environment, the technical gesture tends to compensate the hiatus between man and environment, to the point that man's world, which ought to be in principle symbolic, can be once again viewed as a sort of a "neoenvironment". It is quite reasonable: i) the biological liberation implies the freedom of the hand, which means the possibility of the technological acting; ii) this acting is symbolic since it is based on the paradigmatic model; iii) it enables a long chain of exteriorizations; iv)there we find the peculiar separation man-environment, but the symbolic character of the technological gesture paradoxically implies a refill of that distance (Cera 2013, 181-192), since the tool is used to remedy a biological lack; v) machines are the ultimate expression of this development, because they allow a definitive domination onto what is supposed to be absolutely far from man.

${ }^{10}$ The main difference between Cassirer and Leroi-Gourhan might be found in the worth given to the final goal of their genealogies. Indeed, the ethical man has a spiritual primacy in Cassirer's mind, and becomes the truly man, since it reaches the realm of Geist and his transcendent disposition (Cassirer 2004, 237-255; Renz 2002, 92-106; Bermes 2012, 593-598); according to Leroi-Gourhan, instead, the idea that the ethical man descends from his twofold biological roots (both from anatomical biology and from biology of society) seems to be always predominant.
} 
ontology is an ontology of what is not present, since the beable-content ${ }^{11}$ is evidently defined as a product of reason in its transcendental and mathematical structure. Thinking being means to individuate the position of that being among the other beings; this intrinsic mathematical character of knowledge compels us to recognize the functionality of knowledge, and the fact that the presence of being is always a sort of logic postulate. The meta-environmental element is then present in the basic foundation of ontology too. Notwithstanding, it is in An Essay on Man that the intrinsic tension toward the future becomes evident. This orientation is accomplished when politics and ethics, as forms of culture, are definitely sketched. The problem of moral acting is based on the definition of previsions and rules, transcending the punctual disposition of experience as such. This dynamics finally ends with the determination of the regulative character of the idea of Good, which works as the polar star of the acting, but which is not reachable at all. From this point of view, politics and ethics could be solely in a non-place, because their real goal is not properly available, and they work as directional systems (Cassirer 1944, 84-86).

The real character of future is that of being unavailable: the tension of human acting is directed toward an ungraspable foundation working as criterion of activity. Of course, this is an already specialized form of acting, and it cannot be used as the wellspring of the human activity as such. However, the symbolic character of the Good can be interpreted as the final stage of a whole phenomenology, whose roots remount the first development of the technological capacity, through Neoanthropians and looking back at Palaeoanthropians. The meta-environmental character of that technological gesture sets up the conditions for the realization of human transcendence, viz. the conditions of possibility of the basic move of going beyond the immediateness of experience; the biological worth of this tension is indispensable for the surviving and adaptation of human kind. The meaning of the human gesture expands to the point that Cassirer can call the peculiar chronological dimension to which it belongs: "symbolic future" (Cassirer 1944, 77-79), whereas he refuses to recognize that this symbolic attitude pertains to animal chronological determination:

On the basis of this evidence it seems to follow that the anticipation of future events and even the planning of future actions are not entirely beyond the reach of animal life. But in human beings the awareness of the future undergoes the same characteristic change of meaning which we have noted with regard to the idea of the past. The future is not only an image; it becomes an "ideal". [...] It is more than expectation; it becomes an imperative of human life (Cassirer 1944, 78).

\footnotetext{
${ }^{11}$ The content that could be assumed as a potential being becoming an actual being. The term is taken from Bell's classic work on quantum mechanics: "The beables of the theory are those elements which might correspond to elements of reality, to things which exist" (Bell 2004, 174).
} 
The cultural turn makes of the record of the mechanical operational sequences a completely different question. The human acting is not only based on the solidification of a memory and on doing the right choice among a class of operations, but in its cultural meaning directly deals with an utopian tension, which Cassirer manifestly calls "prophetic". From this point of view, the religious and ethical acting can be viewed as the last stage of an evolution, which began with the setting of an operative code.

\section{Technology, Language and Symbolic Faculty}

I have tried to show the circularity between technological and symbolic action (Ruin 2012, 120-121), and aimed at endorsing a transcendental foundation of the analysis of human acting - which I will explain in details in the next paragraph. The comparison of the philosophical argumentation to palaeoanthropology has provided a renewed scientific basic for the philosophical argumentation, which tends to tie the different aspects of technology, of social and cultural assets, of ontology and ethics. Nevertheless, the proposal of integrating the classic definition of man as rational being with the genealogical argument of the "technological man", does not disprove the centrality of the definition of "animal symbolicum". The symbolical disposition is indeed confirmed by LeroiGourhan, when he claims that the invention of graphism is the late distinctive element of man's evolution (Leroi-Gourhan 1993, 187-200); accordingly, the definition "animal symbolicum" appears to gain a fascinating solidity.

Let me conclude by summing up the content of a paragraph from Gesture and Speech (Leroi-Gourhan 1993, 112-116). It deals with the relationship language-technology, but will allow us to point out once again the validity of the definition of man as "animal symbolicum" and its meta-environmental tension. The objective is to lay the foundations of a theory of acting according to which technological and symbolical actions are solely two aspects of the same phenomenon. Considering the complexity of the matter, I will divide the summary in three parts.

i) Language, symbols and signs. The first question to face is what we properly consider as "language". Cassirer has showed that "human language" is characterized by a symbolic and meta-environmental tension, connected to the rise of the question of meaning; animals do have a specific language, but its function is solely that of manifesting interior feelings or needs. This emotional communication does not reach the logical form and the meta-environmental status, since it is not possible to conceive "sign" as a stable content to be used in another context. Hence, the peculiarity of human language is that of being based on the creation of "symbols" - Cassirer distinguishes human "symbols" from animal "signs" or "signals" (Cassirer 1944, 47-50)-, and the invention of 
writing is the natural and decisive evolution of the whole process. Indeed, when men could only speak, there was a strict division between the hand and the facial pole, despite the fact that human language has been born in function of the adaptation of the face to the anatomical configuration of the skeleton and to the freedom of the hand; the rise of writing then means a sort of reconciliation between hand and face, to the point that Leroi-Gourhan clearly claims that tools and words are the product of the same human faculty ${ }^{12}$ (LeroiGourhan 1993, 113-114). Technological and symbolical actions are unavoidably interconnected since the beginning of human evolution, and one can say that they are solely two words for the same thing.

ii) Technology, language and symbolical tension. The relationship between technology and symbolics is so deep that it precedes the rise of language too. If one might envisage a purely mute technological education, a symbolization has to be invoked as well, since the meta-environmental tension constitutionally belongs to the technological gesture (considering the paradigmatic model). This allows us to conceive the rise of language as going hand in hand with the development of the technological gesture, which brings us to think that Archanthropians and Palaeoanthropians, until the homo sapiens, had developed the language they could speak, considering their own technological expertise. The symbolical tension of language is the same as that animating the birth of technology. Indeed, it is important that human language overcames the mere level of "vocal signals": "Where comparative studies of tools and skulls tell us that the rate of development of industry corresponded to that of biological development, language must have been very primitive indeed, but it undoubtedly amounted to more than vocal signals" (Leroi-Gourhan 1993, 114). This is a solid proof of Cassirer's argumentation on the specificity of human language. As I have already written above, the language of apes is characterized by the fact that communication ceases with the situation within which the "signal" has been created; this also means that it is not available for future operations, and that it is not a sign as such:

The characteristic trait of the "language" and "techniques" of the great apes is that they are resorted to spontaneously in response to an external stimulus and are just as spontaneously abandoned, or fail to appear, if the material situation triggering them ceases to exist or does not occur. The making and using of choppers or bifaces must be ascribed to a very different mechanism since the operations involved in making a tool anticipate the occasions for its use and the tool is preserved to be used on later occasions. The same is true of the difference between signal and word, the permanence of a concept being comparable to that of a tool although its nature is not the same (Leroi-Gourhan 1993,114).

12 Philosophy of technology had already underlined this mutual relationship between tools and words (see Eyth 1924, 12). 
The resemblance to Cassirer's point of view is absolutely impressive. The sentence on the chopper confirms this argumentation: technology is nothing but a symbolic scheme of reproduction, based on the constant availability of an operative code. The character of Bestand (Heidegger 2000, 5-36) of the technological being depends on the stable work of the technological acting. Moreover, the symbolic character of technology is proved by the mutual implication of gesture and tool: the coordination of both originates a sort of semiotics of technology, and, even better, validates the fact that technology itself is symbolical. In favour of the latter conclusion, also speaks Leroi-Gourhan's integration of the mechanism technology-language with a third aesthetical dimension (Leroi-Gourhan 1993, II, 269-280).

iii) The unity of the symbolical dimension and the meta-environmental tension of human acting. The symbolic character of language is then evident since the Neanderthalians, and sets up the conditions of possibility of specific stages of human culture, the first one of which is of course religion. The contiguity of technology and symbolics compels us to understand the development of language as the development of a system, containing the rules through which the operations with signs have been made possible. Accordingly, language is logics, viz. a codified structure of technological operations with signs. However, it is once again needed to stress the uniqueness of the symbolical dimension, from which technology and language depart as branches of the same tree. Let me conclude by saying that the meta-environmental qualification of this dimension is undoubtedly upheld by Leroi-Gourhan too:

We seem to have lost nothing of what may have been our remote kinship with the trilobite or the earthworm. Every element of psychological organization that the vertebrate needs for its vital balance we need too. But all these elements are the steering wheel that steers our vegetative activity behind what is particular and peculiar to ourselves alone: our symbolizing faculty [...], that property of the human brain that consists in maintaining a distance between lived experience and the organism that serves as its medium. The problem of the dialogue between the individual and society, which has come up in connection with the question of intelligence and instinct [...] is nothing other than this capacity human beings have of distancing themselves from their environment, both external and internal (Leroi-Gourhan 1993, II, 234235).

Nevertheless, it must be pointed out that the "meta-environmentality" argument is not new in the history of the philosophical anthropology. As is well known, a meta-environmental definition of the human acting has been stressed by Gehlen in the same years of Cassirer (Gehlen 1988, 24-32). However, there is still a difference between Cassirer and the great philosophical anthropologists and between these ones and Leroi-Gourhan's approach. In the 
first case, as Bermes has pointed out, Cassirer focuses on the analysis of the technological acting as distinctive characteristic of man, rather than asking the question on the worth of technology for men; to him, technology is not the answer to a biological lack, but a specific and original attitude tied to the symbolic faculty (Bermes 2012, 592). In Leroi-Gourhan, technology has in turn manifested its biological root, so that, in the light of the biology of technology and society, the ethical destination cannot be conceived as the real human dimension at all. Strictly speaking, ethical freedom would remain, to LeroiGourhan, a biological product: we may wholly understand the meaning of this tendence, if we will be able to consider the latter as a transposition of the biological scheme into a new situation, in which the biological chains appears to be definitely overcome, but according to which a general and functional structure of the acting is confirmed. On the contrary, from Cassirer's point of view, the direction of the symbolization function, although it appears to be biologically founded, goes downward, and its constitutive aspect for the originally human acting seems to aftwerwards imply a whole metabasis eis allo genos (Bermes 2012, 595; Möckel 2005, 342-343). It is correct to state that within the human acting there has been a special overthrow of the biological nature, but this special upturning can never be seen as a sort of removed element of the identity of mankind. Hence we are obliged to review Cassirer's theory, in order to correct and specify the phenomenological aim of his approach.

\section{The Transcendental Grounding of the Human Acting}

On what basis a transcendental foundation of the human acting can be justified? In order to answer this question, we can give a look at the very source of the transcendental argument on acting, viz. Kant's Kritik der praktischen Vernunft. The starting point of the second Critique consist of the indubitable existence of an a priori moral law (Kant 1990, A 56-57; A 81), as well as, in the field of scientific knowledge, we began from the universal laws of nature; but in the case of the natural knowledge we must admit that the a priori functions of reason are limited in accordance with our experience, and this does not happen with the moral acting. When we are answering the question "What we have to do?", we must put aside the influence of sensitivity on the formulation of the judgement motivating our action (Kant 1990, A 38-40). The analysis of the logical structure of the moral commands is quite clear, and it hardly deserves a comment: the choice of individuating the very meaning of the acting in the "categorical imperatives" does not leave room for uncertainty. However, the purity of moral reason does not imply the annihilation of the biological dimension, insofar as the sensitive stimuli are not deleted, but they rather result to be overcome under the action of moral reason (Kant 1990, A 57-58). Every time we are ethically acting, this does not mean that we do not experi- 
ence the sensitive world of our feelings or needs; on the contrary, we consciously decide to withhold it after having tasted its inflammatory roots. Hence the "withholding" of the natural world within the moral acting is far from implying the cancellation of the sensitive nature, and it rather means the constant and progressive overshooting of the latter.

If we imagine applying this "scheme of the overshooting" to the palaeontological scale, we might depict a broadened version of the critical theory of acting, as though we encountered a specific degree of symbolization of the biological world for each stage of the acting. Considering the whole range of LeroiGourhan's and Cassirer's theories, we may envisage a progressive empowerment of the symbolic function, so that from the first pole of the acting to the last one the distance between the biological starting point and its relative degree of symbolization has widened and reached its final form. We can schematize as follows: 


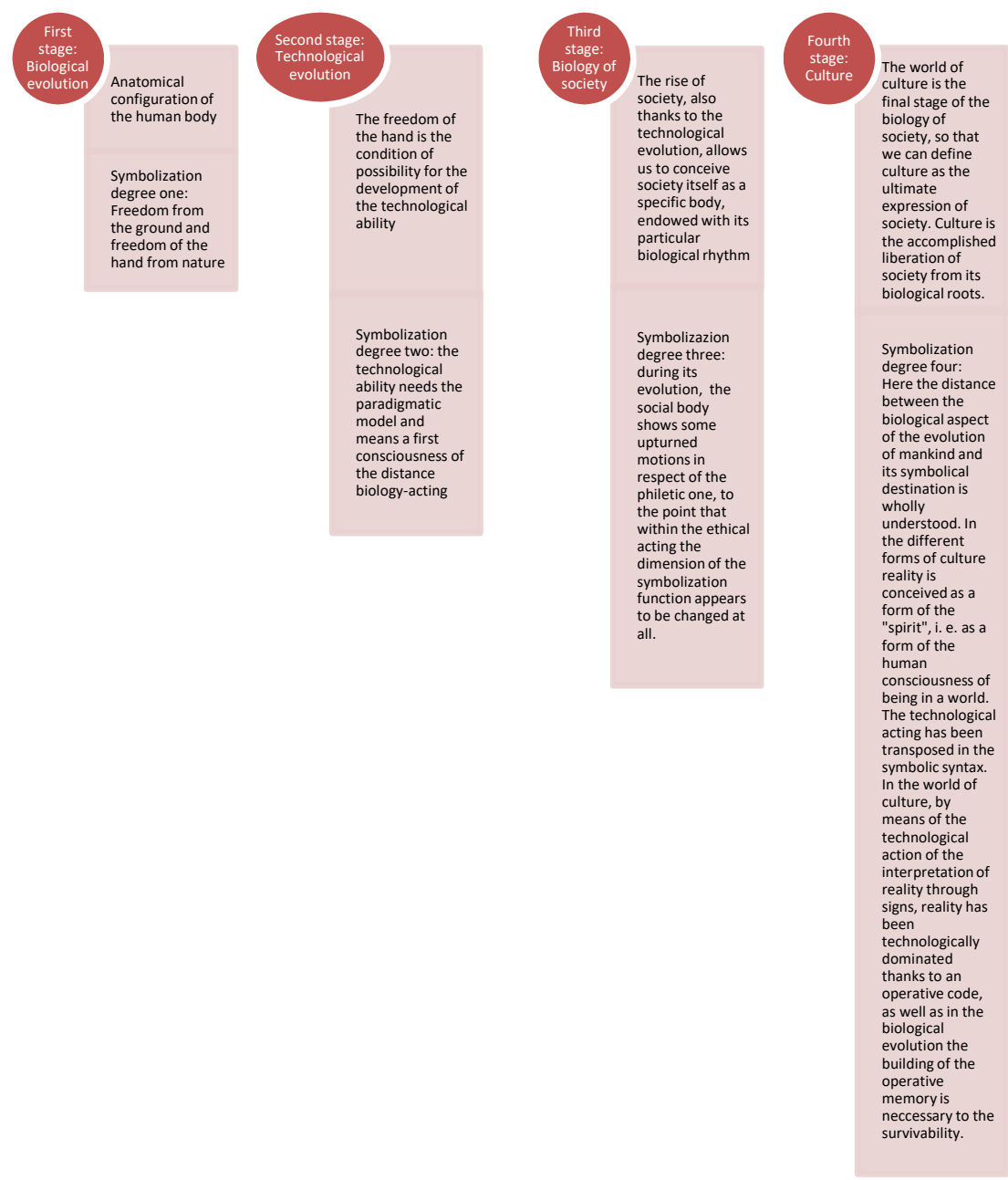

Therefore, we ascertain the greater gap between biology and culture in the fourth stage, but the process of liberation has become in the deepest nest of the belonging of man to nature: even in his first steps on Earth, man appears to be a vector of freedom, since his biology involves a special impulse for the overcoming of the biology of nature. Kant himself, in Anthropologie in pragmatischer Hinsicht, conceived the technological disposition as the first characteristic moment of the human identity, together with the pragmatic disposition and the moral one; he even explicitly admitted that the human reason is somehow shaped on the basis of the form and of the organization of the hand (see the starting quote of the paper: Kant 1880, 255), since the structure of the latter seems to imply a sort of indetermination, which prepares man to the use of reason (Gebrauch der Vernunft). The lack of specialization of the 
hand sharpens the human wits, and do correspond to an extended capacity of dominating reality through intelligence, which then in its first meaning is technology. It is not by chance, indeed, that the reason is something we use in order to gain a knowledge of our environment, that through this act can become what we are used to call "external reality" or simply "reality"13. Human biology is in itself a first degree of separation from the biology of nature: the process still goes on, until man realizes his complete separation from his own biology, in the perception that in the world of ethics he has to stare at the pure contemplation of the ideals of the acting (the idea of social justice, of equality, of human rights etc.; Kant 1880, 255-257). In the world of culture, within the field of figurative arts and in the highest expressions of spirit in general, there is no doubt that the symbolization function is far from the biological origin of the species, insofar as we would not propend for conceiving the "Monna Lisa" as an exclusive product of the neurophysiological stimuli and responses guiding the hand of the painter. There the symbolic nature of our being in the world is completely explained. At the same time, the shape of the human biology penetrates in the world of culture too, since the old technological paradigm appears to be transposed in the function of symbolization. The technological gestures according to which men were used to model matter and create tools had to depend onto the setting of an external idea of the working of the tool itself. This is the idea of the action the tool has to carry out, and it implies the consolidation of the meaning of the action as an independent element of the action itself: this paradigm might be perhaps modified during the use of the tool, but it works as a goal the tool must accomplish, if it has to be a good

\footnotetext{
${ }^{13}$ Luft has however noticed that Kant's anthropology sets up a different point of view than that argued in the transcendental philosophy, since the empirical commitment of the former undermined the a priori status of the latter (Luft 2015, 382). His review of the transcendental grounding of anthropology addresses the question of an a priori of culture, to be found in the common elements of invariance among different mythical representations (Luft 2015, 390-399). It is clear that this is not our approach; on the contrary, we seek a condition of possibility in the biological framework, in order to show that the function of symbolization is already at work in the deepest roots of our physiological origin. The reconstruction of the a priori, starting from the invariants within the mythical stories, is certainly an interesting and fruitful attempt at building a universal picture of the symbolic reality of myth, but it limits itself to a second-hand description. We might indeed point out that the reconstruction goes through the language in which the stories are told: this means that we always face an interpretation, even though we would be able to follow the general dynamics of the setting of a prototype of all these stories, and to put it as a model of the human mind. On the contrary, our aim at presenting a sort of physiological theory of the transcendental dimension of the human acting, by means of the analysis of the technological faculty, would like to tie the empirical and the rational sphere, arguing the existence of a general form of acting, whose inner disposition is strictly symbolic, since its biological beginning. It is solely why the freedom of the hand from the ground is already symbolic, that in the world of culture we can recognize those peculiar liberations leading man into the realm of the a priori as a ultimate expression of that ancient freedom.
} 
instrument. It is more the instrument that depends on the paradigm than the paradigm to be shaped by the tool.

If we finally analyze one of the highest forms of culture, i. e. ethics, into which we would not have to encounter any shadow of the sensitive reality, we may indeed observe that the general structure of the acting mirrors the scheme of the technological gesture. The external paradigmatic idea is, in this case, the presumption of an idea of Justice, whose name is not as important as its plain existence - it might be called "God" and nothing would change -: as in the technological dimension we tried to adequate the tools to their function, in the ethical actions we seek the moral perfection through the attempt of adapting our acting to Justice or Good. Between the goals of the technological actions and those of the ethical ones there is only a substantial difference, whereas, from a structural point of view, we are always acting in order to reach a perfect performance of the action. The perfection of the action obviously depends on the adaptation degree of the tool to the idea the tool must give tangible form, as well as the perfection of a moral action is strictly connected to its adequacy to perform the pure idea of Justice. In Kant's transcendental foundation of ethics this is precisely argued through the idea of "the highest Good" (Kant 1990, A 194; A 198-203). Nevertheless, it is crucially important to underline that the whole system stands because a perfect adequacy is in principle impossible: as the ethical actions could not grasp the pure idea of the moral acting, in which the aim of the acting is perfectly adequate to its ultimate meaning (the union of "virtue" and "happiness") ${ }^{14}$, the technological actions cannot completely adapt themselves to the idea of the acting. The creation of a chopper does not exhaust the general idea of cutting, just as a good action does not mean the totality of the moral acting. If we were able to refill that distance, the acting would cease in the stasis of a pure contemplation and the dynamical spirit of life would be annihilated.

The transcendental status of the acting does mean the inexhaustibility of action: we have a paradigmatic model, that we cannot touch with our own hands, and that works as a sort of horizon we will never able to walk on. The function of the paradigm consists of its unachievable essence and compels us to constantly seek the perfect adaptation of our will to the contempt of the abstract

\footnotetext{
14 This depends on the inner structure of the moral acting, i. e. on the fact that the overshooting never means the annihilation of the sensitive sphere; the solution of the basic antinomy of the practical reason is indeed the setting of two postulates, enabling the access to the realm of the highest Good. These postulates do not address any actual existence of immortal substances (soul and God), but they solely imply the urgent hypothesis of their own function: motivating our action toward the perfection of the moral meaning, that would be otherwise ungraspable. The same concept of the highest Good is meant by Kant as "Beförderung" (Kant 1990, A 205), viz. as a promoted goal by the practical reason, in order to justify the fact that a virtuous action could also be a source of happiness and not a mere mortification of the sensitive reality, to which feelings and needs are tied.
} 
idea: this is the only reason why we can keep acting. It is clear that we solely act because we can never cease to act: only if we can look for something ungraspable we will continue our research to embrace it. Furthermore, it is remarkable that this capacity of setting an independent goal from the sensitive reality is, in the $\S 83$ of the Kritik der Urteilskraft, the very element of human culture $^{15}$ as system of the overshooting of this reality (Kant 1922, 509-514).

Hence it is not by chance that the technological acting and the ethical one appear to be based on the same structurally functional circle, even though from the zoological technology to the symbolic ethics many things are changed. But the fact that we cannot remember those old times in which flavours were pleasanter than ever, does not mean that everything has been lost under the frozen ground of a betrayed youth of the spirit. The biological memory has been transposed in the fully symbolic acting, and the scheme is now shaped according to a perfect clarification of what was implicit before, but in the symbolic acting we find the same structural characteristics of the biological action. We act staring at a goal we will never reach, as well as our actions are tools modelled on the idea of a superior form of the moral acting, viz. the idea of Justice.

\section{Conclusion}

Cassirer directly deals with the question of the proximity between technology and symbolics. A 1930s essay, Form und Technik, addresses the question, and elaborates a theory of the spiritual acting, according to which the plastic capacity of technological action implies a symbolical tension. Tools witness above all a "Grundrichtung des Erzeugens" (basic direction of the producing), and an analogy between technology and language is manifestly developed, since they are both means of the "Bemächtigung der Wirklichkeit" (appropriating of reality). Human activity is based on mediation, and Spirit itself, as distinctive attribute of human life, is a mediating form (Bayer 2001, 41-51). Cassirer points out that man is at the same time "vernünftig" (reasonable) und "werkzeugbildend" (creator of tools), as though the definition of man as "animal rationale" or "animal symbolicum" and that of "homo technologicus" were two manifestations of the same attitude, intended as the unity of an "Akt des 'Fassens'" (act of grasping) or as "bildendes Gestalten" (creative forming). The consolidation of the relationship between the technological and the symbolical sphere is confirmed by the consideration of the paradigmatic model of the

\footnotetext{
15 From this point of view, the definition of "culture" is exhaustive: "Die Hervorbringung der Tauglichkeit eines vernünftiges Wesens zu beliebigen Zwecken überhaupt (folglich in seiner Freiheit) ist die Kultur: The creation of the suitability, to a reasonable being, for the setting of a goal at will (namely in his freedom) is culture" (Kant 1922, 511).
} 
technological action, where the meta-environmental element is clearly depicted:

In its pure logical form, all thought is mediated. It is directed to the discovery and extraction of a mediating structure, which joins the opening sentence and the ending sentence of a communicative chain. The tool fulfils the same function, represented here in the logical sphere, in the objective sphere of physical objects. [...] It sets itself between the first positions taken by the will and its goal. Only in this in-between position is it permitted to separate them and set them at a proper distance. As long as the human being makes use only of his limbs, his bodily "organs", in order to achieve his goals, such distancing is not yet reached. [...] In the tool and its application, however, the goal sought-after is for the first time moved off into the distance. Instead of looking spellbound at this goal, the human being learns to "fore-see" it. This form of seeing is all that distinguishes human intentional doing from animal istinct. The "fore-seeing" establishes "fore-thought" (Die «Ab-Sicht» begründet die «Voraus-Sicht»). It establishes the possibility of directing attention to a goal, towards something spatially absent and temporally remote, rather than acting on an immediately given sensuous stimulus. It is not so much because animals are inferior to the human in bodily skill. But because this line of sight is denied to animals, there is no genuine tool use in the area of animal existence (Cassirer 2012, 30-31).

The resemblances of Cassirer's quote to Leroi-Gourhan are quite evident. The technological acting is thoroughly transposed into a "Distanzierungsprozeß" (Falkenburg 2012, 576-577; Bermes 2012, 593) which seems to be perfectly comparable to Leroi-Gourhan's dialectics of "liberation" and "exteriorization". The liberation from the anatomical limits and the progressive departing of the tool from its manual root, implies, as in Leroi-Gourhan did, the consideration of the constitutive role of technology and lead to a phenomenology which, from the tool to the machines, realizes the maximal exteriorization (LeroiGourhan 1993, II: 243-256). It is quite peculiar that the biological start of technology ends in a world of pure machines, but this argument ceases to be paradoxical if one remembers that the freedom from biology is the distinctive character of human evolution.

Moreover, Cassirer focuses on the teleological worth of the paradigm, and not directly on its ontological status, but the two aspects are obviously interconnected: the paradigm is a form, but the form is tied to the goal that must be accomplished through the tool. The position of the paradigm/goal finally entails the recognition of the meta-environmental tension: future becomes henceforward the specific dimension of human temporality as consequence of this meta-environmental disposition and of the symbolic nature of human activity. Tools and words are instead subject to the codification within a system of operations, regulated by memory and organized under the leadership of brain in its relationship with the material environment. 
In conclusion, one must say that palaeontology has deeply confirmed the worth of Cassirer's definition of "animal symbolicum", but it has also showed that it is urgent to integrate it with a specific genealogy of the technological faculty. However, technology and symbolics are two actualizations of a whole dimension: calling it "technological" or "symbolical" is solely a matter of opinion. Accordingly, I have suggested to rename the unity of these spheres as "meta-environmental" dimension. It follows from this analysis that the chronological determination of man basically belongs to the future, and that it ends in the realization of its utopian tension - ethics is the ultimate form of the technical gesture as well as machines are the late exteriorization of manual technology.

\section{Literature}

Aristotle 1998. Politics, tr. by C. D. C. Reeve. Indianapolis - Cambridge: Hackett. Aristotle 2015. Physics, tr. by R. P. Hardie \& R. K. Gaye. Adelaide: University of Adelaide Library.

Audouze, F. 2002. Leroi-Gourhan, a Philosopher of Technique and Evolution. Journal of Anthropological Research, 4 (2002), 277-306.

Bayer, T. I. 2001. Cassirer's metaphysics of symbolic forms. New Haven - London: Yale University Press.

Bell, J. S. 2004. Speakable and Unspeakable in Quantum Mechanics. Cambridge: Cambridge University Press.

Bermes, C. 2012. Technik als Provokation zur Freiheit. Cassirers Konzeption einer Anthropologie der Technik. In B. Recki (Hg.) Philosophie der Kultur - Kultur des Philosophierens. Ernst Cassirer im 20. und 21. Jahrhundert. Hamburg: Meiner Verlag, 583-599.

Cassirer, E. 1944. An Essay on Man. An Introduction to a Philosophy of Human Culture. New Haven: Yale University Press.

Cassirer, E. 1950. The Problem of Knowledge. Philosophy, Science and History since Hegel, tr. by W. H. Woglom \& C. W. Hendel. New Haven: Yale University Press.

Cassirer, E. 1957. The Philosophy of Symbolic Forms. III: The Phenomenology of Knowledge, tr. by R. Manheim. New Haven - London: Yale University Press.

Cassirer, E. 1998. Leibniz' System in seinen wissenschaftlichen Grundlagen. Gesammelte Werke, Bd. 1, ed. by M. Simon. Hamburg: Meiner Verlag.

Cassirer, E. 1999. Das Erkenntnisproblem in der Philosophie und Wissenschaft der neueren Zeit. Erster Band. Gesammelte Werke, Bd. 2, ed. by T. Berben. Hamburg: Meiner Verlag.

Cassirer, E. 2003. Zur Meraphysik der symbolischen Formen, tr. by G. Raio, Metafisica delle forme simboliche. Milano: Sansoni. 
Cassirer, E. 2004. Determinismus und Indeterminismus in der modernen Physik. Historische und systematische Studien zum Kausalproblem. Gesammelte Werke, Bd. 19, ed. by C. Rosenkranz. Hamburg: Meiner Verlag.

Cassirer, E. 2012. Form and Technology. In A. Sissel Hoel \& I. Folkvord (eds) Ernst Cassirer on Form and Technology. Contemporary Readings. Basingstoke (UK): Palgrave \& Macmillan, 15-53.

Cera, A. 2013. Tra differenza cosmologica e neoambientalità. Sulla possibilità di un'antropologia filosofica oggi. Napoli: Giannini.

Coccia, E. 2014. Il bene nelle cose. La pubblicità come discorso morale. Bologna: il Mulino.

Cohen, H. 1987. Kants Theorie der Erfarhung. Cohens Werke, ed. by H. Holzhey, Bd. I. 1. Hildesheim: Olms.

de Villers, B. 2007. La condition techno-logique de l'homme. In P. Piret (ed.) La littérature à l'ère de la reproductibilité technique. Réponses littéraires au niveau dispositif représentatif crée par les médias modernes. Paris: L'Harmattan, 89-102.

Eyth, M. 1924. Lebendige Kräfte. Sieben Vorträge aus dem Gebiete der Technik. Berlin: Springer.

Falkenburg, B. 2012. Wissenschaft und Technik als symbolische Formen. In B. Recki (Hg.) Philosophie der Kultur - Kultur des Philosophierens. Ernst Cassirer im 20. und 21. Jahrhundert. Hamburg: Meiner Verlag, 567-582.

Ferrari, M. 1996. Ernst Cassirer. Dalla scuola di Marburgo alla filosofia della cultura. Firenze: Olschki.

Ferrari, M. 2003. Categorie e a priori. Bologna: il Mulino.

Gehlen, A. 1988. Man. His Nature and Place in the World, tr. by C. McMillan \& K. Pillemer. New York: Columbia University Press.

Heidegger, M. 2000. Vorträge und Aufsätze, in Gesamtausgabe, Bd. 7. Frankfurt/M.: Klostermann.

Helmholtz, H. von. 1867. Handbuch der physiologischen Optyk. Leipzig: Voss.

Ibongu, G. 2011. Cassirer's Structural Realism. Berlin: Logos Verlag.

Itzkoff, S. 1971. Scientific Knowledge and the Concept of Man. Notre Dame: University of Notre Dame Press.

Kant, I. 1880. Anthropologie in pragmatischer Hinsicht, 3. Auflage, ed. by J. von Kirchmann. Leipzig: Koschny.

Kant, I. 1911. Metaphysische Anfangsgründe der Naturwissenschaft. Kants gesammelte Schriften, ed. by A. Höfler, vol. IV, Berlin: Akademie der Wissenschaften.

Kant, I. 1922. Kritik der Urteilskraft, in Kants Werke, ed. by O. Buek, vol. V. Berlin: Bruno Cassirer.

Kant, I. 1990. Kritik der praktischen Vernunft, ed. by K. Vorländer. Hamburg: Meiner Verlag.

Kant, I. 2013. Kritik der reinen Vernunft [1781/1787]. Stuttgart: Reclam. 
Kriszat, G. \& von Uexküll, J., 1956. Streifzüge durch die Umwelten von Tieren und Menschen, Hamburg: Rowohlt.

Leroi-Gourhan, A. 1971. Evolution et téchniques, I: L'homme et la matière [1943]. Paris: Albin Michel.

Leroi-Gourhan, A. 1993. Gesture and Speech [1964-1965], I: Technics and Language; II: Memory and Rhythms, tr. by A. Bostock Berger. Cambrigde (USA) - London: MIT Press.

Luft, S. 2015. The a priori of Culture: Philosophy of Culture Between Rationalism and Relativism. The Example of Lévi-Strauss' Structural Anthropology. In J. Tyler Friedman \& S. Luft (eds) The Philosophy of Ernst Cassirer. A Novel Assessment. Berlin - Boston: De Gruyter, 381-400.

Möckel, C. 2005. Das Urphänomen des Lebens. Ernst Cassirers Lebensbegriff. Hamburg: Meiner Verlag.

Plato 1998. Cratylus, tr. by C. D. C. Reeve. Indianapolis \& Cambridge: Hackett.

Plato 2000. Timaeus, tr. by D. J. Zeyl. Indianapolis \& Cambridge: Hackett.

Plümacher, M. 1996. Die Einheit der Regel der Veränderung. Zur Bedeutung der Wissenschaftsrezeption für Cassirers Theorie des Wissens. In M. Plümacher \& V. Schürmann (Hg.) Einheit des Geistes. Probleme ihrer Grundlegung in der Philosophie Ernst Cassirers. Frankfurt/M.: Peter Lang Verlag, 113-140.

Portmann, A. 1956. Vorwort zu Kriszat, G. \& von Uexküll, J. Streifzüge durch die Umwelten von Tieren und Menschen. Hamburg: Rowohlt.

Renz, U. 2002. Die Rationalität der Kultur. Zur Kulturphilosophie und ihrer transzendentalen Begründung bei Cohen, Natorp und Cassirer. Hamburg: Meiner Verlag.

Ruin, H. 2012. Technology as Destiny in Cassirer and Heidegger: Continuing the Davos Debate. In A. Sissel Hoel \& I. Folkvord (eds) Ernst Cassirer on Form and Technology. Contemporary Readings. Basingstoke (UK): Palgrave \& Macmillan, 113-138.

Schacht, R. 2015. Gehlen, Nietzsche, and the Project of a Philosophical Anthropology. In P. Honenberger (ed.) Naturalism and Philosophical Anthropology. London: Palgrave MacMillan 49-65.

Simmel, G. 19222. Lebensanschauung. Vier metaphysische Kapitel [1918]. München - Leipzig: Duncker \& Humblot.

Sissel Hoel, A. 2012. Technics of Thinking. In A. Sissel Hoel \& I. Folkvord (eds) Ernst Cassirer on Form and Technology. Contemporary Readings. Basingstoke (UK): Palgrave \& Macmillan, 65-91.

von Uexküll, J. 1928. Theoretische Biologie. Berlin: Springer-Heidelberg. 
Luigi Laino

(Università di Napoli Federico II, llain031@gmail.com)

\begin{abstract}
Man and Future: A Palaeontological and Chronological Foundation of Cassirer's Definition of Man As "Animal Symbolicum"
\end{abstract}

\begin{abstract}
In the present paper, the author aims at laying the foundations of a symbolics of technical gesture, according to the thesis that symbolic faculty is another face of the technological one, and that they are both in truth two sides of the same coin. Accordingly, the author suggests to rename the whole dimen-sion as "meta-environmentality". The analysis is carried out on the basis of a specific comparison between Cassirer's definition of "animal symbolicum" and its scientific consistence in the light of modern palaeontology. "Animal symbol-icum" is here compared with Leroi-Gourhan's homo technologicus, and Cassi-rer's ideas on human identity tested starting from paleoanthropological data. The result of the inquiry lead us to recognize the urgency of integrating Cassi-rer's argument with the primacy of the technological capacity, but a deep anal-ysis of the characterizing attributes of the latter compels us to uphold the symbolic attitude of the technological dimension. The author then sketches a basic description of the guidelines of a symbolic theory of technology (espe-cially §§ 6-7), and tries to show how the basic elements of such an approach were familiar both to Cassirer and Leroi-Gourhan. As a consequence of the whole theory, the author elaborates a chronological analysis of human identity, whose basic result is the determination of the future as main temporal dimen-sion of human acting.
\end{abstract}

Keywords: Philosophy of Culture, Philosophical Anthropology, Philosophy of Palaeoanthropology, Cassirer, Leroi-Gourhan.

Ethics in Progress (ISSN 2084-9257). Vol. 8 (2017). No. 1, Art. \#2, pp. 12-40.

Creative Commons BY-SA 3.0

Doi: 10.14746/eip.2017.1.2 